\title{
Case Study on Computer-aided Multi-functional Charging Equipment Liu Guo-qing
}

Wenzhou Vocational \& Technical College, Wenzhou. 325035

3685424@qq.com

Keywords: mobile phone;charging;device;color;time.

\begin{abstract}
. 1/3 of global consumers will be intelligent mobile phone users to 2018 and the total number will be more than 2560000000 . Mobile phone charging will certainly be a major problem in future society, especially charging in public. This paper analyzes and comments the development status as well as various existing problems of public universal charging of mobile phones, and bases on this to design a mobile phone charging equipment which is appropriate in public through using the professional knowledge I learn at school.
\end{abstract}

\section{Introduction}

After stepping into the twenty-first century, electricity has become an essential part in our daily life and we cannot image how to spend our days without electricity. Put aside that our demands in production and life could not be met, the small mobile phones can only become the bricks which we may only use to "smash walnut". In addition, mobile phone has become necessity for both at home or travel outside. We can find that mobile phone charging will be a big problem in the future society, especially in public places.

\section{Acceptance project and feasibility analysis}

With the reform and opening up, rapid development of national economy as well as continuous improvement of living standards, people have a increasing demand for electronic products. On the same time, they also have a increasing demand for the performance of electronic products, mobile phone replacement is particularly prominent, from the original mobile phone, clam-shell to current intelligent mobile phone. But the following question is that they have a more and more high demand for mobile phone battery. There is no doubt that the huge power consumption of intelligent mobile phones has become a measure which has an urgent to reform, mobile phone charging seems to be the thing we have to face every day.

\subsection{Put forward design task}

When entering in the twenty-first century, our society has steeped into information age. China has become the country that has the largest number of mobile phone users which is now increasing year by year. Almost everybody has a mobile phone, and you will find that no matter on the streets, in the cars or shopping malls, there are plenty people who are lowering their heads and playing mobiles. In addition, you will also find that they will get into troubles of no power supplying when talking or playing the key points. Especially in nowadays, the consumption speed of mobile phone power is becoming more and more quick, our timely supply demand for mobile charging is more and more urgent. People are not so satisfied with existing mobile charging facilities, and they cannot satisfy the demand to a maximum extent. As a result, issues about mobile phone charging are more and more obvious, and people have an urgent demand for this.

\subsection{Clear nature and features of the users}

Most mobile phone users are the youth and even some carry two mobile phones. Most users will use mobiles in casual and the frequency is about ten minutes each time. What is more, they mainly use for making a phone call or playing the games with huge power consumption. Even a full charged mobile phone cannot meet our demands which will directly affect the people who have something important to tell, and people will doubt about the second purchasing. 


\subsection{Market status of public universal charging}

Now the public universal charging have already been widespread in the stations, shopping malls and other public places where people gather. While they have too simple structures and too dull colors, although they can meet the charging demand of most mobile phones, they need to put in the coins and one yuan may only charge for ten minutes which cannot meet the demands. In addition, all these charging devices have not provided seats and wire and models of charging devices are mess, it is very difficult to distinguish the suitable charging mode. There is no large universal mobile phone charging station outside and people feel difficult to find a charging device in public places. When taking photos with phones or playing mobile games in the park, we have to choose the using time to avoid emergency.

\subsection{Project feasibility analysis}

1) Huge market capacity

2) Less required funds

3) Predictable and controllable risk range

4) Mainly develop the function of keeping pace with the times

\subsection{Analysis report}

We can find according to the research situation: types of the mobile phone charging station on the current market are relatively simple. In addition, quality, structure and charging satisfaction are uneven. Some charging stations are money machines in essence, they does not provide any convenient for people. On contrast, they bring troubles to people and take up unnecessary resources space.

People have an urgent need for a mobile phone charging station that can meet the requirements of most people, it is convenient to charge and leisure. Soft colors, texture materials and beautiful curve may bring different people different psychological feelings.

\section{Design expression}

\subsection{Modeling is shown in figure 1}

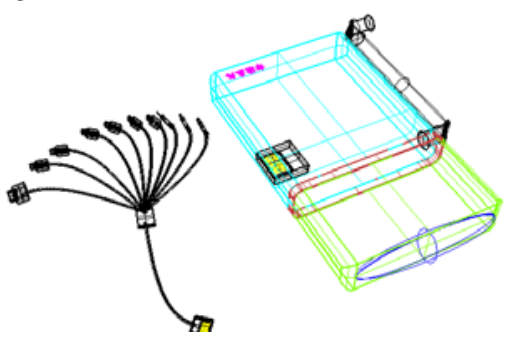

Figure 1 Modeling

\subsection{Charging head effect is shown in figure 2}

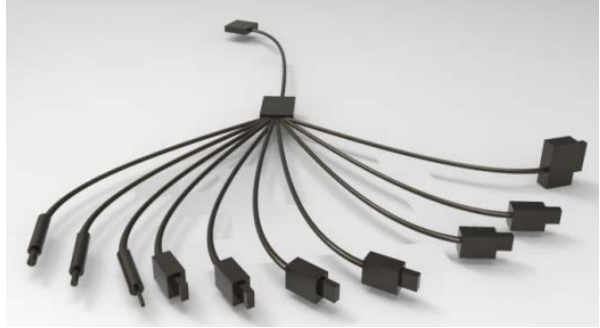

Figure 2 Charging head effect 


\subsection{Detail display is shown in figure 3}

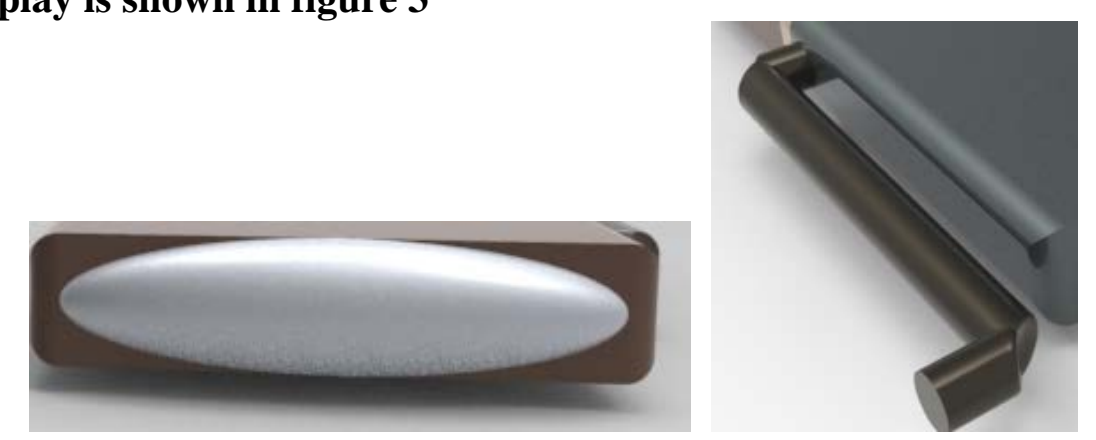

Figure 3 Detail display

\subsection{The effect chart is shown in figure 4}

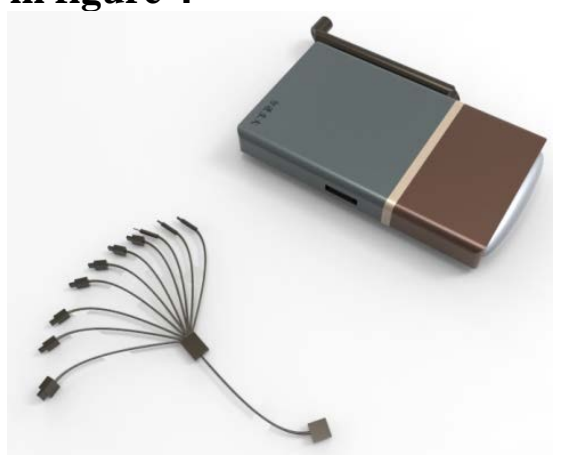

Figure 4 Effect chart

\section{Design concept}

\subsection{Design principle}

Development and design of public mobile phone charging station need to firstly clearly defined the population as well as the construction site. According to the market analysis report, construction sites of charging stations are set in the city streets and park squares, and the target group are all mobile phone users. In terns of power source, I use the principle of solar power generation. As we all know, solar energy belongs to green clean energy which is consistent with green production and green travel we advocate now. According to the various required charging conditions under different circumstances such as: emergency phone, rest demand and WIFI surfing demand, it will provide the best quality service according to different situations. As a result, charging station shall have safety, comfort, easy operation, interaction between human and machine and other features, and take all the situations we will encounter when charging into consideration.

As a design for mobile phone, it should not be single and take all kinds of human factors into account in design. In addition, we should have a system concept and combine every part together to design a complete and perfect product.

\subsection{Materials selection}

Materials of public universal mobile phone charging station mainly have: 2.0 stainless steel paint processing, PVC, glass and pinewood, etc.

Solar charging board: glass, EVA, TPT and aluminum alloy frame.

Mobile phone charging station: stainless steel frame, PVC auxiliary structure, glass window and pine board seats.

\subsection{Ergonomics analysis}

Although research content and application scope of ergonomics are quite wide, its most prominent feature is that it uses human factor as an important parameter in product design and takes human, machine and environment into consideration. All these provide a scientific method to solve the relationship among human, machine and environment for designers. 


\subsubsection{Human factor}

Human measurement dimension: human measurement dimension includes static and dynamic dimensions. Static dimension refers to the structure dimension of human body; while dynamic dimension refers to function dimension of human body which includes action range, shape change and body mass distribution when exercising.

Mechanical index of human body: it includes force strength, direction, operating speed, operating frequency, accuracy and endurance size of action. We design machines and tools in accordance with the mechanical ability of human beings.

\subsubsection{Machine factor}

Operating system: operating system mainly refers to the device which can accept all kinds of instructions issued by people, people may convey their intentions to the function part and achieve the control of machine through operating system. These devices include not only common operating lever, steering wheel and keyboard controlled by hands, but also advanced eye control system and voice control system such as: voice and text input of computer, helmet mounted sight of fighter aircraft and strictly controlling automatic focusing system of camera.

\subsubsection{Relationship between industrial design and ergonomics}

Industrial design applies relevant research findings about human, machine and environment in ergonomics and ergonomics also provides a real scientific basis for the relationship between human and objects in industrial design. As a result, ergonomics occupies an extremely important position in industrial design. While it is only a link in industrial design and cannot solve all the issues.

\subsubsection{Issues about industrial design application of ergonomics}

Industrial design mainly solves the relationship between people and objects. As a result, application of ergonomics almost touches upon all the fields in industrial design such as: daily necessities, household appliances, computer, transportation, machinery and equipment, etc. All the designs should take the contents about ergonomics into consideration.

Development of modern science and technology makes information exchanges between human beings and machine become more and more. Control activities related to this change original operating mode that people mainly control the machine through manual skills and form a continuous cycle, interactive man-machine system. Wherein, both display design and control design gradually receive attention from people and become a key issue of ergonomics in industrial design application.

\section{Summary}

After taking a wide range of research as well as modifying the program constantly, this design changes the indoor charging and paid charging mode of traditional mobile phone charging station. It moves the charging station to city streets, parks and other public places to make it more close to our daily life. In addition, based on the forgetting function, I add seats, night lighting, wireless charging, wireless WIFI and other functions, and all these make product features more perfect, meet the charging demand better and make our daily life more convenient.

\section{References}

[1] G RIPPE RS V C , MOU LIANIT IS N A , DENTSORAS A T .A M odel f or Concept Evaluati on in Desi gn - an Ap plicati on t o M echat ronics Design of Robot[ D] .M echani cal Engineering an d Aeronauti cs Departm en t, 2003 .

[2] RODGERS Paul A, PAT TERSON Alastai r C ,WILSON Derek R. Concept Design Assessment f rom Specified User Needs[ J] .Integrat ed Manuf acturing Syst ems , 1995 , 6(3):30 -36.

[3] RODGERS Paul A, PAT TERSON Alastai r C ,WILSON Derek R. Concept Design Assessment f rom Specified User Needs[ J] .Integrat ed Manuf acturing Syst ems , 1995 , 6(3):30 -36.

[4] LYU Xin.Research on Product Innovation Design Based on 39 Contradictions Matrices and 40 Innovation Principles of TRIZ [J].Packaing Engineering, 2009，30（5）: 27-30. 